\title{
Real-World Health Plan Data Analysis: Key Trends in Medication Adherence and Overall Costs in Patients with HIV
}

\author{
Anne Kangethe, PharmD, MPH, PhD; Michael Polson, PharmD, MS; Todd C. Lord, PharmD; \\ Themmi Evangelatos, PharmD, MSBA; and Alan Oglesby, MPH
}

\begin{abstract}
BACKGROUND: Adherence to effective antiretroviral therapy (ART) is essential to achieve long-term viral suppression in patients with HIV-1. Singletablet regimens (STRs) have improved adherence and decreased health care costs and hospitalizations, but previous study results suggest that the relationship between ART adherence and health care costs and utilization is complex.
\end{abstract}

OBJECTIVE: To assess ART adherence trends in patients with HIV-1 to determine if differences in utilization, demographics, and overall costs exist among patients with varying levels of medication adherence.

METHODS: This retrospective study analyzed medical and pharmacy claims data from an administrative claims database between January 1, 2007, and June 30,2016 , for Medicaid or commercially insured patients continuously enrolled for $\geq 6$ months before and $\geq 15$ months after the index date (date of first medical claim with an HIV diagnosis or pharmacy claim for HIV ART medication between July 1, 2007, and June 30, 2014). Qualifying patients were aged $\geq 18$ years with a diagnosis of HIV-1 infection or at least 1 pharmacy claim for HIV ART at index and at least 2 pharmacy claims during the follow-up period. Patients were categorized on the basis of adherence as measured by proportion of days covered (PDC; $\geq 95 \%$, highly adherent; $<95 \%$, less adherent) and treatment with an STR or multiple-tablet regimen (MTR). Commercially insured patients were stratified by duration of follow-up data ( $<3$ or $\geq 3$ years). There were not enough Medicaid patients for follow-up analysis. Outcomes of interest were ART adherence and annual medical and pharmacy utilization and costs. Descriptive statistics were generated, and health care resource utilization and costs were reported as annual averages. Chi-square and t-tests were used to examine differences between the cohorts.

RESULTS: A total of 332 Medicaid patients and 1,698 patients insured commercially met inclusion criteria. Adherence to ART medication (mean PDC) during the first 15 months was lower in Medicaid patients (65\%) versus commercial patients $(79 \% ; P<0.0001)$. Patients treated with STRs comprised $47 \%$ and $37 \%$ of patients in the $<3$-year and $\geq 3$-year follow-up cohorts, respectively. More STR patients achieved $\geq 95 \%$ adherence than MTR patients (<3-year follow-up, $53 \%$ vs. $39 \%$; $\geq 3$-year follow-up, $61 \%$ vs. $45 \% ; P<0.001)$. In both follow-up cohorts, less adherent patients had higher mean annual medical costs, and results were significant for patients with $\geq 3$-year follow-up ( $\$ 8,224$ vs. $\$ 3,097 ; P=0.0007)$. These results were largely driven by savings in mean annual inpatient costs among the highly adherent patients in both cohorts (<3-year follow-up, $-\$ 2,525$ $[P=0.0003]$; $\geq 3$-year follow-up, $-\$ 815[P<0.001])$.

CONCLUSIONS: Patients on STRs were more adherent than patients on MTRs regardless of length of follow-up. Better adherence was associated with significant inpatient cost savings. The relationship between adherence and total medical costs is nuanced depending on the duration of follow-up.

J Manag Care Spec Pharm. 2019;25(1):88-93

Copyright $\odot 2019$, Academy of Managed Care Pharmacy. All rights reserved.

\section{What is already known about this subject}

Strict adherence to antiretroviral therapy (ART) is essential to achieve durable clinical outcomes in patients with HIV-1 and minimize drug resistance and virologic failure.

According to previous studies in real-world settings, which had mean follow-up of approximately 1 year, the introduction of single-tablet regimens (STRs) to reduce pill burden resulted in improved ART adherence and decreased health care costs and hospitalizations for patients with HIV-1 compared with multipletablet regimens (MTRs).

The relationship between adherence and health care costs may be more complex than these studies suggest, as demonstrated by 1 analysis that showed higher total health care costs over a 24-month period for asymptomatic HIV-positive patients who were at least $90 \%$ adherent compared with those who were $<90 \%$ adherent to ART.

\section{What this study adds}

This study provides insight into the longer-term relationship between ART adherence and health care costs, demonstrating that, after $\geq 3$ years of ART, highly adherent patients incurred lower mean annual medical costs, driven primarily by savings in inpatient costs, compared with less adherent patients.

The study results add to the growing body of literature demonstrating that STRs are associated with higher adherence to ART than MTRs.

Compared with commercially insured patients, patients with Medicaid insurance had a lower ART adherence rate and a greater number of comorbidities.

1 he Centers for Disease Control and Prevention estimate that more than 1.1 million people in the United States are living with human immunodeficiency virus (HIV)-1, with approximately 39,782 new HIV diagnoses in 2016 and 6,721 deaths attributed directly to HIV in 2014. ${ }^{1}$ Deaths from HIV infection have declined across the United States since the introduction of highly active antiretroviral therapy (ART). ${ }^{2}$

Adherence to ART is essential to achieve durable virologic suppression and minimize drug resistance., 3,4 An adherence rate of $95 \%$, widely cited as the minimum rate necessary to maintain HIV-1 viral load suppression of $<400$ copies/mL, has 
been associated with fewer days in the hospital and reduced morbidity and mortality compared with lower adherence rates. ${ }^{5,6}$

A variety of factors can negatively affect medication adherence among people living with HIV (PLWH), such as complexity of the regimen (e.g., pill burden and dosing frequency), concerns about side effects, overall mental or physical health, and other patient-related and sociodemographic variables. $^{7-9}$ The introduction of single-tablet regimens (STRs) to reduce pill burden has resulted in improved adherence and decreased health care costs and hospitalizations for PLWH compared with multiple-tablet regimens (MTRs) in real-world settings. ${ }^{6,10-13}$ However, the relationship between adherence and health care costs may be more complicated than previously thought. For example, Pruitt et al. (2015) found that, over a 24-month period, total health care costs were significantly higher for ART-adherent ( $\geq 90 \%$ ), asymptomatic HIV-positive patients compared with nonadherent $(<90 \%)$, asymptomatic HIV-positive patients. ${ }^{14}$ These investigators called for further research to examine the long-term association of ART adherence with total health care costs.

This study assessed ART adherence trends in PLWH and determined if differences in utilization, demographics, and overall costs exist among patients with varying levels of medication adherence.

\section{Methods}

\section{Study Design and Data Source}

A retrospective cohort design was implemented using data from a medical and pharmacy administrative claims database (Magellan Rx Management, Middletown, RI) from multiple regional health plans (Medicaid and commercial) in the United States between January 1, 2007, and June 30, 2016. The index date was the date of the first medical claim with an HIV diagnosis code or pharmacy claim for an HIV medication during the index period (July 1, 2007-June 30, 2014). Baseline metrics were measured in the 6-month period before the index date, and patients were followed for at least 15 months after the index date. ART adherence and health care costs and utilization were assessed annually following the index date.

\section{Inclusion Criteria}

Patients who met all of the following criteria were included: (a) HIV diagnosis (International Classification of Diseases, Ninth Revision, Clinical Modification [ICD-9-CM] codes 042 or International Classification of Diseases, Tenth Revision, Clinical Modification [ICD-10-CM] code B20) or asymptomatic HIV infection (ICD-9-CM code V08 or ICD-10-CM code Z21) in the index period or at least 1 pharmacy claim for HIV ART at index; (b) at least 2 pharmacy claims for HIV medication during the follow-up period; (c) aged $\geq 18$ years on the index date; and (d) continuous eligibility for medical and pharmacy

\begin{tabular}{|c|c|c|c|}
\hline & $\begin{array}{l}\text { Commercial } \\
\text { Insurance } \\
(\mathbf{n}=1,698)\end{array}$ & $\begin{array}{l}\text { Medicaid } \\
(\mathrm{n}=332)\end{array}$ & $P$ Value \\
\hline $\begin{array}{l}\text { Age, years, mean (SD) } \\
\text { [median] }\end{array}$ & 46.5 (10.6) [47.2] & $43.4(11.2)[44.5]$ & $<0.0001$ \\
\hline \multicolumn{4}{|l|}{ Age range, $\mathrm{n}(\%)$} \\
\hline $18-29$ & (8.8) & $48 \quad(14.5)$ & \multirow{6}{*}{$0.0011^{\mathrm{a}}$} \\
\hline $30-39$ & $255 \quad(15.0)$ & $64 \quad(19.3)$ & \\
\hline $40-49$ & $597 \quad(35.2)$ & $109 \quad(32.8)$ & \\
\hline $50-59$ & $536 \quad(31.6)$ & $95 \quad(28.6)$ & \\
\hline $60-69$ & $151 \quad(8.9)$ & $(4.5)$ & \\
\hline $70+$ & $(0.5)$ & $(0.3)$ & \\
\hline \multicolumn{4}{|l|}{ Sex, n (\%) } \\
\hline Female & $349 \quad(20.6)$ & $203 \quad(61.1)$ & \multirow{2}{*}{$<0.0001$} \\
\hline Male & $1,349 \quad(79.4)$ & $129 \quad(38.9)$ & \\
\hline \multicolumn{4}{|l|}{ CCI score, n (\%) } \\
\hline 0 & $1,228 \quad(72.3)$ & $157 \quad(47.3)$ & \multirow{4}{*}{$<0.0001^{b}$} \\
\hline 1 & $266 \quad(15.7)$ & $91 \quad(27.4)$ & \\
\hline 2 & $120 \quad(7.1)$ & $38 \quad(11.4)$ & \\
\hline$\geq 3$ & $84 \quad(4.9)$ & $\begin{array}{ll}46 & (13.9) \\
\end{array}$ & \\
\hline $\begin{array}{l}\text { CCI, mean (SD) } \\
\text { [median] }\end{array}$ & 0.5 (1.1) [0.0] & 1.1 (1.6) [1.0] & $<0.0001$ \\
\hline \multicolumn{4}{|c|}{ Comorbidities of interest, $n$ (\%) } \\
\hline $\mathrm{HCV}$ & (4.9) & $58 \quad(17.5)$ & $<0.0001$ \\
\hline MDD & $134 \quad(7.9)$ & $73 \quad(22.0)$ & $<0.0001$ \\
\hline \multicolumn{4}{|c|}{ Adherence, mean (SD) [median], \% } \\
\hline PDC & $79(26)[88]$ & $65(29)[70]$ & $<0.0001$ \\
\hline \multicolumn{4}{|l|}{ Regimen, n (\%) } \\
\hline MTR & $999 \quad(58.8)$ & $247 \quad(74.4)$ & $<0.0001$ \\
\hline STR & $699 \quad(41.2)$ & $85 \quad(25.6)$ & $<0.0001$ \\
\hline \multicolumn{4}{|c|}{$\begin{array}{l}\text { aP value represents the difference in the percentage of younger patients in the } \\
\text { Medicaid population compared with the commercial insurance population. } \\
\text { bP value represents the difference in the percentage of Medicaid patients with } \\
\geq 2 \text { comorbidities at baseline compared with the commercial insurance population. } \\
C C I=\text { Deyo-Charlson Comorbidity Index; HCV=hepatitis } C \text { virus; } M D D=\text { major } \\
\text { depressive disorder; } M T R=\text { multiple-tablet regimen; } P D C=\text { proportion of days } \\
\text { covered; } S D=\text { standard deviation; } S T R=\text { single-tablet regimen. }\end{array}$} \\
\hline
\end{tabular}

coverage from 6 months before the index date through at least 15 months after the index date. For patients using STR tenofovir disoproxil fumarate/emtricitabine, an additional HIV diagnosis was required for inclusion.

\section{Study Outcomes}

The study outcomes of interest were ART adherence and annual medical and pharmacy utilization and costs. Adherence was measured by proportion of days covered (PDC), calculated by the available days of supply of a dispensed medication from pharmacy claims data relative to the follow-up time for each individual patient. ${ }^{15}$ PDC was calculated for each patient's individual antiretroviral product. For patients classified as using MTR, the average PDC was used to characterize the adherence. 
Real-World Health Plan Data Analysis: Key Trends in Medication Adherence and Overall Costs in Patients with HIV

TABLE 2 Baseline Characteristics of Commercially Insured Patients, Stratified by Duration of Follow-up

\begin{tabular}{|c|c|c|c|c|c|c|c|c|}
\hline & \multicolumn{4}{|c|}{$<3$-Year Data } & \multicolumn{4}{|c|}{$\geq 3$-Year Data } \\
\hline & All $(\mathrm{N}=686)$ & STR $(n=322)$ & $\operatorname{MTR}(\mathbf{n}=364)$ & $P$ Value & All $(\mathrm{N}=1,012)$ & $\operatorname{STR}(\mathbf{n}=377)$ & $\operatorname{MTR}(n=635)$ & $P$ Value \\
\hline Age, years, mean (SD) & $45.10(11.21)$ & $42.52(11.81)$ & $47.38(10.13)$ & $<0.0001$ & $47.49(10.12)$ & $45.15(10.99)$ & $48.88 \quad(9.30)$ & $<0.0001$ \\
\hline Female sex, n (\%) & $124 \quad(18.1)$ & $37 \quad(11.5)$ & $87 \quad(23.9)$ & $<0.0001$ & $225 \quad(22.2)$ & $72 \quad(19.1)$ & $153 \quad(24.1)$ & 0.0721 \\
\hline CCI, mean (SD) & $0.60 \quad(1.20)$ & $0.52 \quad(0.97)$ & $0.68 \quad(1.37)$ & 0.0699 & $0.43 \quad(0.99)$ & $0.35 \quad(0.81)$ & $0.48 \quad(1.08)$ & 0.0247 \\
\hline \multicolumn{9}{|l|}{ ART class, $\mathrm{n}(\%)$} \\
\hline NRTI & $664 \quad(96.8)$ & $322(100.0)$ & $342 \quad(94.0)$ & $<0.0001$ & $987 \quad(97.5)$ & $377(100.0)$ & $610 \quad(96.1)$ & $<0.0001$ \\
\hline NNRTI & $371 \quad(54.1)$ & $249 \quad(77.3)$ & $122 \quad(33.5)$ & $<0.0001$ & $636 \quad(92.7)$ & $354 \quad(93.9)$ & $282 \quad(44.4)$ & $<0.0001$ \\
\hline PI & $229 \quad(33.4)$ & $0 \quad(0.0)$ & $229 \quad(62.9)$ & $<0.0001$ & $405 \quad(40.0)$ & $(0.0)$ & $405 \quad(63.8)$ & $<0.0001$ \\
\hline INSTI & $252 \quad(36.7)$ & $94 \quad(29.2)$ & $158 \quad(43.4)$ & 0.0001 & $304 \quad(44.3)$ & $46 \quad(12.2)$ & $258 \quad(40.6)$ & $<0.0001$ \\
\hline
\end{tabular}

Adherence was assessed at PDC $\geq 95 \%$. Near perfect adherence ( $95 \%$ or greater) has been demonstrated to have greater optimized virologic outcome for patients with HIV infection. ${ }^{5}$

Annual medical utilization and costs were assessed by patient count; visit count; total costs; cost per patient; and patient count by procedure codes of interest, segregated by site of care identifed by place of service code, as well as relevant procedure codes (i.e., hospital, emergency department, and office) and classified as medical costs, pharmacy costs, and total costs.

Baseline patient characteristics were assessed, including age; sex; comorbidities (Deyo-Charlson Comorbidity Index [CCI score]); hepatitis C virus (HCV) coinfection; severe and persistent mental health disorders (i.e., schizophrenia, bipolar disorder, and major depressive disorder); and concomitant medications (by class).

\section{Cohort Assignment}

Each patient was categorized on the basis of ART regimen pill burden (STR or MTR). In the health care cost analyses, commerically insured patients were further divided into 2 cohorts on the basis of length of available follow-up data ( $<3$ or $\geq 3$ years).

\section{Statistical Analysis}

Descriptive statistics were calculated to describe all baseline variables. Mean, median, and standard deviation (SD) were calculated for continuous variables, and categorical variables were characterized by count and percentage. Health care utlization and costs, reported as annual averages, were analyzed using only the commercial population because of the low number of patients in the Medicaid group in the $\geq 3$-year follow-up cohort $(n=24)$. For medical and pharmacy data, cost information was based on allowed amounts for claims. Costs were segregated by site of care, classified as medical costs and pharmacy costs, and aggregated as total costs. Utilization metrics included number of visits to various sites of care and number of prescription fills. To determine differences in categorical variables, the chisquare test was used. Differences in continuous variables were examined by using the t-test. All analyses were performed using SAS software version 9.4 (SAS Institute, Cary, NC).

\section{Results}

The analysis included 332 patients with Medicaid insurance and 1,698 patients with commercial insurance. The Medicaid group had a higher comorbidity burden, determined by the mean (SD) CCI, compared with the commercial group (1.1 [1.6] vs. 0.5 [1.1], respectively; $P<0.0001)$ and a higher incidence of $\mathrm{HCV}(17.5 \%$ vs. $4.9 \%$ respectively; $P<0.0001)$ and major depressive disorder (22.0\% vs. $7.9 \%$, respectively; $P<0.0001$; Table 1). Adherence to ART, as determined by PDC mean (SD), over the first 15 months was lower in the Medicaid group (65\% [29\%]) compared with the commercial group (79\% [26\%]; $P<0.0001)$.

Among the patients with commercial insurance, 686 had $<3$ years, and 1,012 had $\geq 3$ years of follow-up data (mean follow-up time, 2.1 vs. 4.7 years, respectively; Table 2). Patients receiving STRs represented $47 \%$ of patients with $<3$ years and $37 \%$ of patients with $\geq 3$ years of follow-up. Mean overall ART adherence was significantly higher among STR patients compared with MTR patients in both follow-up cohorts ( $<3$-year, $53 \%$ vs. $39 \%$, respectively; $\geq 3$-year, $61 \%$ vs. $45 \%$, respectively; $P<0.0001$ for both comparisons). Similarly, a greater proportion of STR patients in the $<3$-year and $\geq 3$-year follow-up groups achieved $\geq 95 \%$ adherence ( $14 \%$ and $20 \%$, respectively) compared with MTR patients ( $6 \%$ and $5 \%$, respectively; Table 3 ).

Less adherent patients in both cohorts had numerically lower pharmacy costs compared with highly adherent patients (Table 4). This difference was significant for the cohort with $\geq 3$ years of follow-up data (PDC $<95 \%, \$ 18,794$; PDC $\geq 95 \%$, $\$ 26,771 ; P<0.0001)$. 


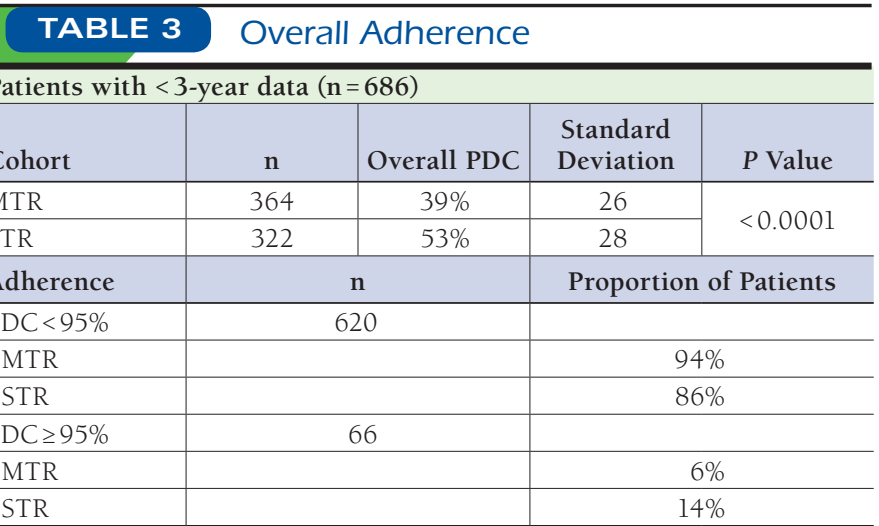

\begin{tabular}{|c|c|c|c|c|}
\hline \multicolumn{5}{|c|}{ Patients with $\geq 3$-year data $(n=1,012)$} \\
\hline Cohort & $\mathrm{n}$ & Overall PDC & $\begin{array}{l}\text { Standard } \\
\text { Deviation }\end{array}$ & $P$ Value \\
\hline MTR & 635 & $45 \%$ & 28 & \multirow{2}{*}{$<0.0001$} \\
\hline STR & 377 & $61 \%$ & 31 & \\
\hline Adherence & \multicolumn{2}{|c|}{$\mathrm{n}$} & \multicolumn{2}{|c|}{ Proportion of Patients } \\
\hline $\mathrm{PDC}<95 \%$ & \multicolumn{2}{|c|}{906} & & \\
\hline MTR & & & \multicolumn{2}{|c|}{$95 \%$} \\
\hline STR & & & \multicolumn{2}{|c|}{$80 \%$} \\
\hline $\mathrm{PDC} \geq 95 \%$ & \multicolumn{2}{|c|}{106} & & \\
\hline MTR & & & \multicolumn{2}{|c|}{$5 \%$} \\
\hline STR & & & \multicolumn{2}{|c|}{$20 \%$} \\
\hline
\end{tabular}

MTR = multiple-tablet regimen; $P D C=$ proportion of days covered; STR $=$ singletablet regimen.

In both follow-up cohorts, less adherent patients had numerically higher mean annual medical costs (excluding pharmacy costs) compared with highly adherent patients, and this difference was statistically significant for the $\geq 3$-year follow-up cohort (less adherent patients, $\$ 8,224$; highly adherent patients, $\$ 3,097 ; P=0.0007$ ). In addition, statistically significant cost savings were realized in mean annual inpatient costs among highly adherent patients in both cohorts: $-\$ 2,525$ in the $<3$-year follow-up cohort ( $P=0.0003$ vs. nonadherent patients); $-\$ 815$ in the $\geq 3$-year follow-up cohort $(P<0.001)$. However, there was no statisital differences observed in the totoal costs between the highly adherent and nonadherent patients.

\section{Discussion}

This study assessed ART adherence in patients with HIV-1 and its potential association with health care utilization and costs. Patients with Medicaid insurance were less adherent to ART and had a greater number of comorbidities than patients with commercial insurance (Table 1). These findings are not surprising given the socioeconomic challenges typically faced by patients with Medicaid insurance, including lower income, lower literacy rates, poorer nutrition, and less access to transportation and stable housing. ${ }^{7-9,16}$ Many of these challenges intersect with or affect known barriers to medication adher- ence, such as regimen complexity (e.g., pill burden and dosing frequency), concerns about medication side effects, overall mental or physical health, beliefs about ART utility, stigma associated with having HIV, and other patient-related and sociodemographic variables. ${ }^{7-9,17}$

Comparisons between STRs and MTRs among patients with commercial insurance demonstrated significantly higher ART adherence with STRs. These findings are consistent with previous studies that demonstrated superior ART adherence with a single pill per day compared with multiple pills per day. ${ }^{6,10-13}$ In several of these studies, the superior adherence associated with STRs was also associated with a lower risk of hospitalization compared with MTRs. ${ }^{6,11,13}$ For example, an analysis of Medicaid claims data in which 1,797 of 7,381 included patients were treated with an STR showed that STR patients had fewer hospitalizations $(P<0.0012)$ than MTR patients and lower total monthly health care costs than MTR patients $(\$ 2,959$ vs. $\$ 3,544$, respectively; $P<0.0001$; mean follow-up duration, 348 days for STRs, 433 days for MTRs). ${ }^{6}$

Compared with highly adherent patients, less adherent patients in both follow-up cohorts in our study had numerically lower pharmacy costs. Patients in the <3-year follow-up cohort had higher medical costs at lower adherence levels compared with the $\geq 3$-year follow-up cohort, but the difference was not significant. However, inpatient costs were significantly higher for less adherent patients in this cohort $(P=0.0003)$. This is likely attributable to the longer average hospital stays in this cohort because there was no difference in the number of inpatient visits between highly adherent and less adherent patients. In the $\geq 3$-year follow-up cohort, patients with high adherence had significantly lower medical costs (excluding pharmacy costs) compared with less adherent patients (PDC $<95 \%, \$ 8,224$; PDC $\geq 95 \%, \$ 3,097 ; P=0.0007$ ). This cost difference may be the result of the higher average number of inpatient visits and longer hospital stays for less adherent patients compared with highly adherent patients.

Statistically significant effect of ART adherence on medical costs in our study did not manifest until after 3 years of followup. However, similarly to Pruitt et al, ${ }^{14}$ our study indicates that although not statistically significant, the total costs (medical and pharmacy) are higher for patients who are highly adherent compared with patients who are less adherent. This result may be attributed to higher pharmacy costs for the adherent patients in both cohorts.

This health care cost analysis examined the complex relationship between ART adherence and health care costs and utilization over time for commercially insured patients with HIV-1. Patients on STRs were shown to be more adherent than patients on MTRs regardless of the follow-up duration. The lower proportion of Medicaid patients on STRs compared with commercial patients in this analysis may reflect difficulty accessing these medications in the Medicaid population. 
Real-World Health Plan Data Analysis: Key Trends in Medication Adherence and Overall Costs in Patients with HIV

TABLE 4 Annual Health Care Utilization and Costs

\begin{tabular}{|c|c|c|c|c|c|c|c|c|c|c|c|}
\hline \multirow{2}{*}{\multicolumn{2}{|c|}{ Measure }} & \multicolumn{4}{|c|}{ Patients with $<3$-Year Data } & \multicolumn{6}{|c|}{ Patients with $\geq 3$-Year Data } \\
\hline & & $\begin{array}{c}\text { All } \\
(\mathrm{N}=686)\end{array}$ & $\begin{array}{c}\text { PDC }<95 \% \\
(n=620)\end{array}$ & $\begin{array}{c}P D C \geq 95 \% \\
(n=66)\end{array}$ & \multirow{2}{*}{\begin{tabular}{c|c}
$\begin{array}{c}P \\
\text { Value }\end{array}$ \\
0.5535
\end{tabular}} & $\begin{array}{c}\text { All } \\
(\mathrm{N}=1,012)\end{array}$ & \multicolumn{2}{|c|}{$\begin{array}{c}\mathrm{PDC}<95 \% \\
(\mathrm{n}=906)\end{array}$} & \multicolumn{2}{|c|}{$\begin{array}{c}P D C \geq 95 \% \\
(n=106)\end{array}$} & \multirow{2}{*}{\begin{tabular}{|c}
$\begin{array}{c}P \\
\text { Value }\end{array}$ \\
$<0.0001$
\end{tabular}} \\
\hline $\begin{array}{l}\text { Utilization, }{ }^{\mathrm{a}} \\
\text { mean (SD) }\end{array}$ & $\begin{array}{l}\text { Number of } \\
\text { inpatient visits }\end{array}$ & $0.35 \quad(1.75)$ & $0.33 \quad(1.70)$ & $0.50 \quad(2.14)$ & & $0.28 \quad(1.00)$ & 0.30 & $(1.05)$ & 0.08 & $(0.40)$ & \\
\hline & $\begin{array}{l}\text { Average length } \\
\text { of stay }\end{array}$ & $2.98 \quad(4.79)$ & $3.07 \quad(5.00)$ & $2.34 \quad(2.68)$ & 0.0054 & $1.32 \quad(1.43)$ & 1.35 & $(1.44)$ & 0.77 & $(1.10)$ & $<0.0001$ \\
\hline & Outpatient visits & $5.80 \quad(4.53)$ & $(4.61)$ & $5.26 \quad(3.72)$ & 0.2266 & $(4.12)$ & 4.88 & $(4.25)$ & 4.77 & $(2.85)$ & 0.726 \\
\hline & Laboratory visits & $3.05 \quad(4.61)$ & $3.23 \quad(4.79)$ & $1.40 \quad(1.59)$ & $<0.0001$ & $1.66 \quad(5.15)$ & 1.80 & $(5.42)$ & 0.44 & $(0.68)$ & $<0.0001$ \\
\hline & $\begin{array}{l}\text { Emergency room } \\
\text { visits }\end{array}$ & $0.38 \quad(0.86)$ & $0.38 \quad(0.88)$ & $0.29 \quad(0.65)$ & 0.2972 & $0.26 \quad(0.45)$ & 0.26 & $(0.46)$ & 0.19 & $(0.34)$ & 0.0406 \\
\hline \multirow{8}{*}{$\begin{array}{l}\text { Costs, } \\
\text { mean (SD), } \\
\$ b\end{array}$} & Inpatient & $2,690(15,156)$ & $2,933(15,908)$ & $408 \quad(2,237)$ & 0.0003 & $773 \quad(5,775)$ & 859 & $(6,098)$ & 44 & $(192)$ & $<0.0001$ \\
\hline & Outpatient & $860 \quad(1,316)$ & $868 \quad(1,368)$ & $(654)$ & 0.3971 & $781 \quad(2,804)$ & 798 & $(2,959)$ & 631 & $(480)$ & 0.1241 \\
\hline & Laboratory & $1,641(10,740)$ & $1,712(11,281)$ & $976 \quad(1,832)$ & 0.1465 & $1,062 \quad(4,583)$ & 1,148 & $(4,829)$ & 325 & $(794)$ & $<0.0001$ \\
\hline & $\begin{array}{l}\text { Emergency } \\
\text { department }\end{array}$ & $319 \quad(907)$ & $(740)$ & $505 \quad(1,849)$ & 0.3731 & $(561)$ & 250 & (573) & 215 & $(445)$ & 0.4663 \\
\hline & Other costs & $4,956(20,238)$ & $4,759 \quad(17,643)$ & $6,799(36,715)$ & 0.6571 & $4,824(28,787)$ & 5,169 & $(30,199)$ & 1,883 & $(10,425)$ & 0.0217 \\
\hline & Medical & $10,467(32,722)$ & $10,572(32,231)$ & $9,474(37,280)$ & 0.8185 & $7,687 \quad(31,219)$ & 8,224 & $(32,758)$ & 3,097 & $(10,559)$ & 0.0007 \\
\hline & Pharmacy & $23,706(19,689)$ & $23,385(20,049)$ & $26,727(15,728)$ & 0.1145 & $19,630(16,746)$ & 18,794 & $(16,551)$ & 26,772 & $(16,777)$ & $<0.0001$ \\
\hline & Total & $34,173(39,096)$ & $33,957(38,280)$ & $36,201 \quad(46,356)$ & 0.7053 & $27,317(36,850)$ & 27,018 & $(38,324)$ & 29,869 & $(20,209)$ & 0.2244 \\
\hline
\end{tabular}

Medicaid patients may encounter formulary restrictions (e.g., prior authorizations requirements) that may delay access to required regimens, ${ }^{18}$ and they ultimately may not be considered in favor of less costly alternatives.

In the commercial population, overall adherence was low regardless of follow-up period, and the proportion of patients attaining 95\% adherence ranged between 5\%-20\%, depending on regimen (STR or MTR; Table 3). Given the multifactorial nature of medication adherence, access to STRs and other strategies to enhance adherence among patients are critical.

While measurement of medication adherence rates at the population level based on pharmacy claims data is of value for epidemiologic and policy-making purposes, these populationbased measures provide minimal information about individual patients. It is important to promote near-perfect adherence at the individual patient level because of its effect on individual ART effectiveness and on public health issues such as preventing the emergence of treatment resistance and minimizing the risk of HIV transmission.

\section{Limitations}

There are several limitations to consider in interpreting the results of this analysis. First, the analysis is based on real-world claims data, and services performed but not billed are not included in the study (e.g., physician samples for pharmaceutical products and services performed pro bono). Also, although the data assessed were representative of an array of geographic regions, the results may not be generalizable to all regions of the United States. Finally, the relationship between adherence and total medical costs is more nuanced than previously reported and may be affected by the duration of follow-up. Therefore, our results suggest further examination of the effect of improved adherence over a longer period of time on clinical and cost outcomes.

\section{Conclusions}

In this study, overall adherence was less than optimal for patients living with HIV. However, patients on STRs were more adherent than patients on MTRs. The relationship between adherence and total medical costs is more nuanced than previously reported, depending on the length of follow-up. Results suggest further examination of the time dependency of improved adherence to improved clinical and cost outcomes.

\section{Authors}

ANNE KANGETHE, PharmD, MPH, PhD; MICHAEL POLSON, PharmD, MS; TODD C. LORD, PharmD; and THEMMI EVANGELATOS, PharmD, MSBA, Magellan Rx Management, Middletown, Rhode Island. ALAN OGLESBY, MPH, ViiV Healthcare, Research Triangle Park, North Carolina.

AUTHOR CORRESPONDENCE: Anne Kangethe, PharmD, MPH, PhD, Magellan Rx Management, 88 Silva Ln., Tech 4, Middletown, RI 02842. Tel.: 401.344.1107; E-mail: akangethe@magellanhealth.com. 


\section{DISCLOSURES}

This study was funded by ViiV Healthcare, which participated in protocol development, the analysis plan, and interpretation of results but did not have final approval on the decision to publish. Kangethe, Polson, Lord, and Evangelatos are employees of Magellan Rx Management, which was contracted by ViiV Healthcare to conduct the research for this study. Oglesby is an employee of ViiV Healthcare and owns stock in GlaxoSmithKline.

Data from this study were previously presented at AMCP Nexus; October 16-19, 2017; Dallas, TX

\section{ACKNOWLEDGMENTS}

Editorial assistance was provided under the direction of the authors by Angela Cimmino, PharmD; Jeff Stumpf, PhD; and Diane Neer and was funded by ViiV Healthcare.

\section{REFERENCES}

1. Centers for Disease Control and Prevention. HIV in the United States: at a glance. November 29, 2017. Available at: https://www.cdc.gov/hiv/statistics/ overview/ataglance.html. Accessed October 15, 2018.

2. Crum, NF, Riffenburgh RH, Wegner S, et al. Comparisons of causes of death and mortality rates among HIV-infected persons: analysis of the pre-, early, and late HAART (highly active antiretroviral therapy) eras. J Acquir Immune Defic Syndr. 2006;41(2):194-200.

3. Li JZ, Gallien S, Ribaudo H, Heisey A, Bangsberg DR, Kuritzkes DR. Incomplete adherence to antiretroviral therapy is associated with higher levels of residual HIV-1 viremia. AIDS. 2014;28(2):181-86.

4. Bangsberg DR, Acosta EP, Gupta R, et al. Adherence-resistance relationships for protease and non-nucleoside reverse transcriptase inhibitors explained by virological fitness. AIDS. 2006;20(2):223-31.

5. Paterson DL, Swindells S, Mohr J, et al. Adherence to protease inhibitor therapy and outcomes in patients with HIV infection. Ann Internal Med. 2000;133(1):21-30

6. Cohen CJ, Meyers JL, Davis KL. Association between daily antiretroviral pill burden and treatment adherence, hospitalisation risk, and other healthcare utilisation and costs in a US Medicaid population with HIV. BMJ Open. 2013;3(8)
7. Genberg BL, Lee Y, Rogers WH, Wilson IB. Four types of barriers to adherence of antiretroviral therapy are associated with decreased adherence over time. AIDS Behav. 2015;19(1):85-92.

8. Holtzman CW, Brady KA, Yehia BR. Retention in care and medication adherence: current challenges to antiretroviral therapy success. Drugs. 2015;75(5):445-54.

9. Langebeek N, Gisolf EH, Reiss P, et al. Predictors and correlates of adherence to combination antiretroviral therapy (ART) for chronic HIV infection: a meta-analysis. BMC Med. 2014;12:142.

10. Langness J, Cook PF, Gill J, Boggs R, Netsanet N. Comparison of adherence rates for antiretroviral, blood pressure, or mental health medications for HIV-positive patients at an academic medical center outpatient pharmacy. J Manag Care Spec Pharm. 2014;20(8):809-14. Available at: https://www.jmcp. org/doi/10.18553/jmcp.2014.20.8.809.

11. Sax PE, Meyers JL, Mugavero M, Davis KL. Adherence to antiretroviral treatment and correlation with risk of hospitalization among commercially insured HIV patients in the United States. PLoS One. 2012;7(2):e31591.

12. Nachega JB, Parienti JJ, Uthman OA, et al. Lower pill burden and oncedaily antiretroviral treatment regimens for HIV infection: a meta-analysis of randomized controlled trials. Clin Infect Dis. 2014;58(9):1297-307.

13. Scott Sutton S, Magagnoli J, Hardin JW. Impact of pill burden on adherence, risk of hospitalization, and viral suppression in patients with HIV infection and AIDS receiving antiretroviral therapy. Pharmacotherapy. 2016;36(4):385-401

14. Pruitt Z, Robst J, Langland-Orban B, Brooks RG. Healthcare costs associated with antiretroviral adherence among Medicaid patients. Appl Health Econ Health Policy. 2015;13(1):69-80

15. Nau DP. Proportion of days covered (PDC) as a preferred method of measuring medication adherence. Pharmacy Quality Alliance. Available at: http://ep.yimg.com/ty/cdn/epill/pdcmpr.pdf. Accessed October 15, 2018.

16. Taitel M, Fensterheim L, Kirkham H, Sekula R, Duncan I. Medication days' supply, adherence, wastage, and cost among chronic patients in Medicaid. Medicare Medicaid Res Rev. 2012;2(3). Available at: https://www. ncbi.nlm.nih.gov/pmc/articles/PMC4006393/. Accessed October 15, 2018.

17. Schaecher KL. The importance of treatment adherence in HIV. Am J Manag Care. 2013;19(12 Suppl):s231-s37.

18. Raper JL, Willig JH, Lin HY, et al. Uncompensated medical provider costs associated with prior authorization for prescription medications in an HIV clinic. Clin Infect Dis. 2010;51(6):718-24. Available at: https://www.ncbi. nlm.nih.gov/pmc/articles/PMC4892366/. Accessed October 15, 2018. 